\title{
Flood Mapping along the Lower Mekong River in Cambodia
}

\author{
Sarann Ly ${ }^{*}$, Lengthong Kim, Séverine Demerre, and Sokchhay Heng \\ Department of Rural Engineering, Institute of Technology of Cambodia \\ *E-mail: ly.sarann@itc.edu.kh (Corresponding author)
}

\begin{abstract}
Located in Southeast Asia, Cambodia is one of the most disaster prone countries, where flooding rank the top of the natural disaster. Flood affects and threatens not only humans' and animal's life, properties, infrastructures, but it is also an obstacle to the current development. Furthermore, without having the efficient modern technology to predict flood situation in Cambodia, the disaster in this country become more serious. The objective of this research study is to simulate flood inundation area by using software HEC-RAS. HECRAS is a hydraulic model software capable of calculating any hydraulic river study including flood. In this study, the Lower Mekong River with approximately $50 \mathrm{~km}$ length was selected to delineate flood map from 2000 until 2013 and also 10-year return period map. The available data are 11 years of the measured water level at the upstream and downstream stations, 18 surveyed cross-sections and DEM with grid cell size $30 \mathrm{~m}$ x $30 \mathrm{~m}$ were used to understand the recurrence of the floods in the study area. The output from the model was delineated into map including flood extent and flood depth from 2000 until 2013 (without 2009, 2010 and 2012). The results show that flooding varied from year to year; however, the greatest flood was during 2000 and again in 2011. The simulated flood maps were compared with observed data to figure out that the model was accurate for flood mapping. These results will be useful for river engineers, experts, and decision makers to manage river floods.
\end{abstract}

Keywords: Flooding, flood map, HEC-RAS model, Mekong River, return period.

ENGINEERING JOURNAL Volume 22 Issue 1

Received 14 September 2017

Accepted 28 October 2017

Published 31 January 2018

Online at http://www.engj.org/

DOI:10.4186/ej.2018.22.1.269 


\section{Introduction}

Cambodia is one of the countries that is situated in South-East Asia which is located from 102.350 to 107.620 Longitude and from 9.910 to 14.690 Latitude [1]. It is a country which is rather surrounded by mountains ranks: Cardamen mountain chain on the west, Dongrek Mountain on the north and hilly plateau on the East [2]. It makes this country's geography like a bowl while its climate is dominated by tropical wet and dry monsoon with the highest amount of rainfall in the southeast [3]. Rainfall intensity in Cambodia is around 1900 millimeters per year. With its $181035 \mathrm{~km}^{2}, 97.5 \%$ is the land while 2.5 percent is water body [1]. For this 2.5 percent, Mekong River, and Tonle Sap Lake is the largest water bodies that provide crucial benefits to habitants who live around this area. Besides the benefits, people who live around there always have a risk of flood almost every year. According to Mekong River Commission (MRC), flood ranks as the top of weather disaster in Cambodia. It occurs during a rainy season when there is more precipitation and then the water level rises.

In Cambodia, there are many factors that cause flooding. These causes are spread from nature and human activities. Because of Cambodia's topography, it makes this territory plain in the central part while the climate of Cambodia is also wet with high rainfall intensity. These constituents contribute flooding in Cambodia almost every year. Moreover, human activities cause indirectly in flooding of Cambodia. Because of deforestation and urbanization, it leads to climate change. Along with the recent changes in land use and mass urbanization and the underdevelopment of systematic water resource management practices and facilities, have led to a hazard environment. As a result, Cambodia becomes susceptible to numerous ongoing hazards. It becomes one of the most disaster-prone countries in South East Asia and ranked in the top ten countries at most at risk of a disaster [4], these risks include annual hydrological events such as monsoon rains, flooding, and droughts. Flooding damage not only infrastructure and humans' properties but also threaten human and animal life. For example, it caused 247 people to death according to Flood Situation Report 2011 by MRC [5]. In addition, without having the efficient modern technology to predict flood situation in Cambodia, the flood disaster would be more severe. Because the effects of these hazards can be extremely complex, the use of data visualization tools such as hazard mapping allows for a complete understanding of the risks associated with these hazards. Flood Mapping forms part of the foundation of a risk management decision-making process providing information essential to understanding.

The objective of this paper is to simulate flood inundation along the Lower Mekong of Cambodia. This research study involves connecting Geographic Information System Software (GIS) and Hydraulic Analysis Software (HEC-RAS). First, this research study is to prove the efficiency of HEC-RAS Model performance in Flood Mapping. To reach this objective, the flood map on 24 August 2008 is produced (base scenario) and compared with observed data set from the satellite. Then HEC-RAS is used to simulate the flood map from 2000 to 2013 at the peak flow.

\section{Study Area}

This research project is conducted along the Lower Mekong River that flows through a part different city and provinces such as Phnom Penh, Kandal Province, and Prey Veng Province. However, the study area only flows through Khan Mean Chey of Phnom Penh, Kean Svay and Lvea Em District of Kandal and Peam Ro of Prey Veng Province. The river study segment (Fig. 1) starts from the Mekong delta (Chbar Ompov) in Phnom Penh (11.551626 Latitude and $104.953156^{\circ}$ Longitude) to Lower Mekong Part and ends at Kokir Thum Commune, Kean Svay District (11.357252 ${ }^{\circ}$ Latitude and $105.259743^{\circ}$ Longitude). The river width is around 1.5 kilometer with the length of the study river is approximately $50 \mathrm{~km}$ and area 4600 hectares. 


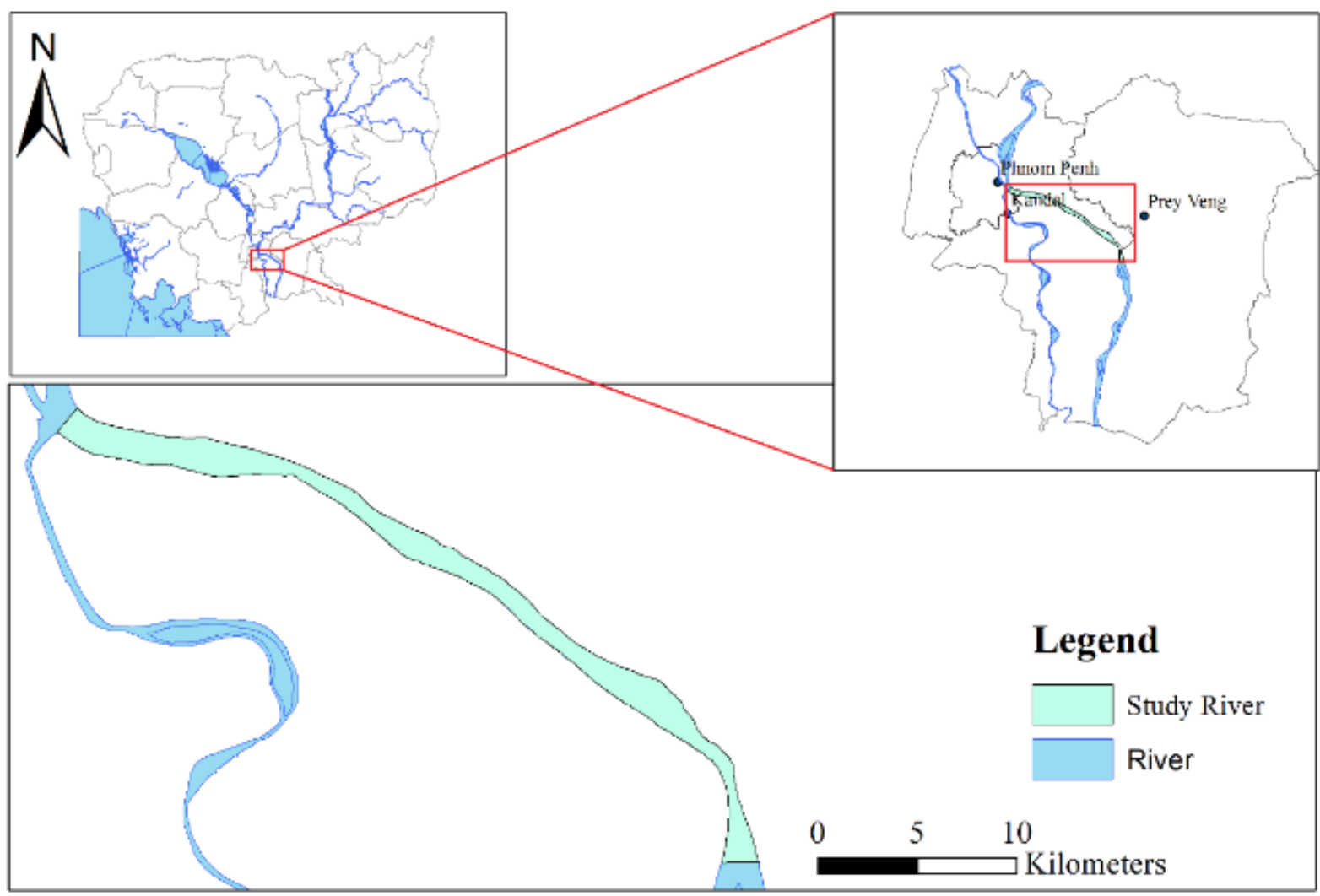

Fig. 1. The Study Area along Lower Mekong River in Cambodia with the approximately length $50 \mathrm{~km}$.

\section{Methodology}

\subsection{Modeling Approach}

Nowadays, there is a wide availability of numerical models with different capabilities and from different developers; some models are free while some others require license purchase. However, one of the most popular hydraulic models is the HEC-RAS (Hydraulic Engineering Center's River Analysis System) developed by the U.S. Army Corps of Engineers (Quiroga et al., 2016). HEC-RAS is an integrated system of software, designed for interactive use in a multi-tasking, multi-user network environment. The system is comprised of a graphical user interface (GUI), separate hydraulic analysis components, data and management capabilities, graphics and reporting facilities. The HEC-RAS system will ultimately contain three onedimensional hydraulic analysis components such as steady flow water surface profile computations, unsteady flow simulation, and sediment transport computations. In addition, HEC-RAS is free of charge software that can openly download from their website while some flood studies model is needed a license purchase. Moreover, HEC-RAS requires less time consuming for simulation. These are sufficient reasons why HECRAS is selected to use to primarily understand flood parameters and characteristic.

For flood forecasting, it is typically based on a two-step process in which a hydrological model is first used to route the flood and determine expected flow at the site of interest [6]. The peak flow from the flood routing analysis is then typically inputted into a steady flow hydraulic model to determine the corresponding flood levels that would be expected along river extending through populated areas.

\subsection{Efficiency of Flood Extent}

To evaluate the performance of the model, the simulated results (affected area) was compared with the observed flood map that was taken by satellite under the copyright of UNOSAT. The performance of the model was evaluated according to the measure of fit value: F1 and F2 [7]. F1 and F2 are the fit that ranges from 0 to 1 and -1 to +1 for $\mathrm{F} 1$ and $\mathrm{F} 2$ respectively. The more $\mathrm{F} 1$ and $\mathrm{F} 2$ value are closer to value 1 (F1, $\mathrm{F} 2>0.5)$ the better model performance is. 


$$
\begin{aligned}
& F 1=\frac{A}{A+B+C} \\
& F 2=\frac{A-B}{A+B+C}
\end{aligned}
$$

\subsection{Water Level Validation}

Furthermore, the simulated results (water level) was assessed by three quantities statistic (Error index), NashSutcliffe Efficiency (NSE), percent bias (PBIAS) and the Ratio of the root mean square error to the standard deviation of measured data (RSR).

Nash-Sutcliffe efficiency (NSE): a normal statistic which is used to determine the relative magnitude of the residual (observed) variance compared to the measured data variance. NSE indicates how well the plot of observed versus simulated data fits the 1:1 line. The following equation is the NSE equation:

$$
\mathrm{NSE}=1-\frac{\sum_{\mathrm{i}=1}^{\mathrm{n}}\left(\mathrm{H}_{\mathrm{obs}_{\mathrm{i}}}-\mathrm{H}_{\text {sim }_{\mathrm{i}}}\right)^{2}}{\sum_{\mathrm{i}=1}^{\mathrm{n}}\left(\mathrm{H}_{\mathrm{obs}_{\mathrm{i}}}-\mathrm{H}_{\mathrm{obs} \text { mean }}\right)^{2}}
$$

Percent-Bias (PBIAS): used to measure the average tendency of the simulated data to be larger or smaller than their observed counterparts.

$$
\text { PBIAS }=\frac{\sum_{i=1}^{n}\left(H_{o b s_{i}}-H_{s i m_{i}}\right) \times 100}{\sum_{i=1}^{n} H_{o b s_{i}}}
$$

RMSE observations Standard deviation Ration (RSR): is used to calculate the ratio of the RMSE and standard deviation of measured data.

$$
R S R=\frac{R M S E}{S T D E V_{o b s}}=\frac{\sqrt{\sum_{i=1}^{n}\left(H_{o b s_{i}}-H_{\text {sim }_{i}}\right)^{2}}}{\sqrt{\sum_{i=1}^{n}\left(H_{o b s_{i}}-H_{o b s m e a n}\right)^{2}}}
$$

where $\mathrm{H}_{\mathrm{obs}}$ is the observation water level, $\mathrm{H}_{\text {sim }}$ is the water level that got from simulation, $\mathrm{H}_{\text {mean }}$ is the average of water level from observed, and $\mathrm{n}$ is the total number of observation and simulated data.

\section{Results and Discussions}

Based on the above methods and data, the Modelling of Lower Mekong River $(50 \mathrm{~km})$ results in the creation of flood extent (area), flood depth as shown in graph and also map with the discussion following:

\subsection{Performance on Flood Extent}

The performance of the model was assessed by comparing the flood simulation with a remotely sensed image from 24th August 2008. To make the analysis and discussion easier, the affected area including river surface was divided into separate communes from three relevant provinces (Phnom Penh, Kandal, Prey Veng). Flood affected 20 communes from these three provinces. 


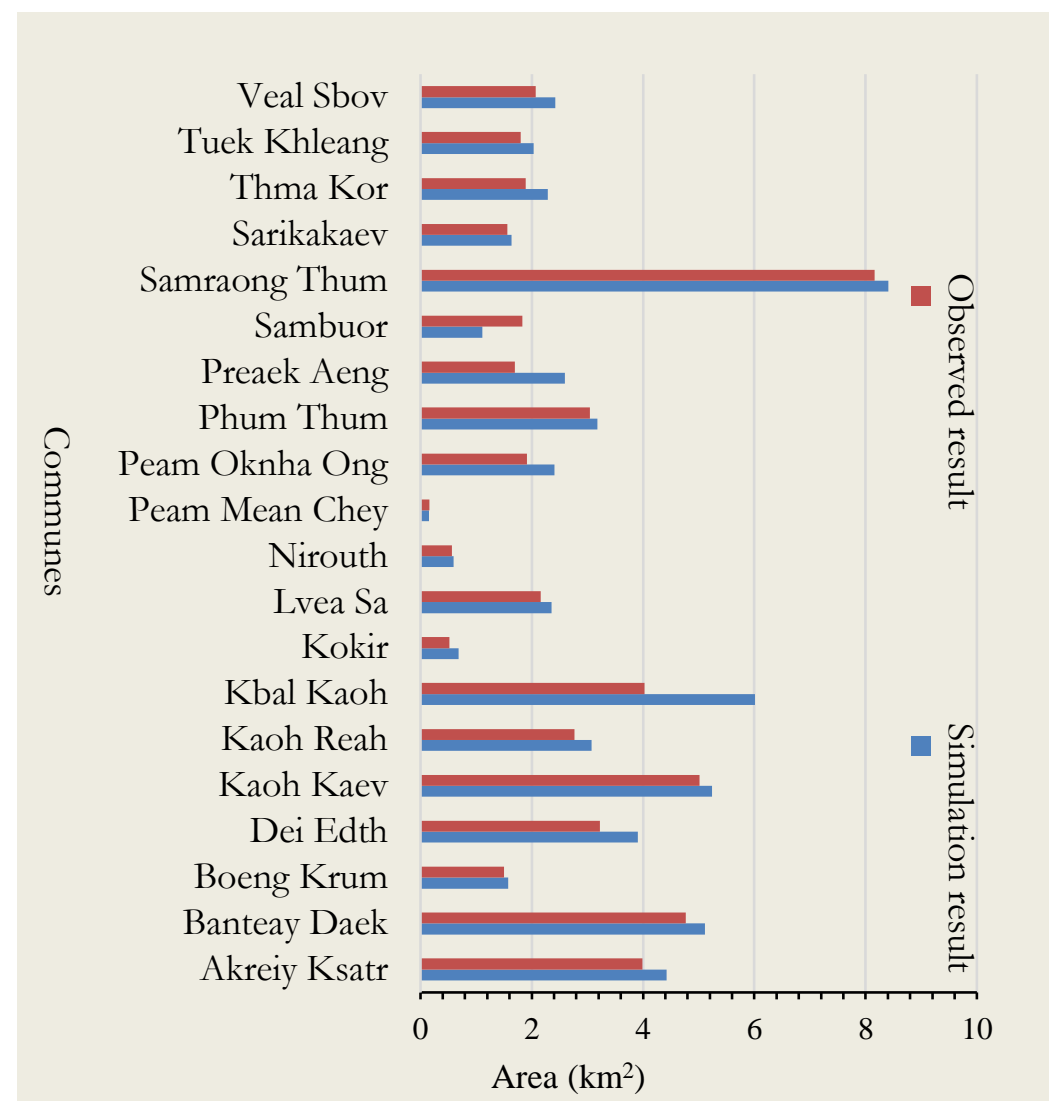

Fig. 2. The Observation and Simulation Results of effected area in $\mathrm{km}^{2}$ from 20 communes among other commune in study area.

According to above graph (Fig. 2), it illustrates the comparison of simulation and observation. In overall, the affected area from the simulation is greater than observation. However, the degree of difference is not too high except the affected area in Kbal Kaoh commune. The difference in Kbal kaoh commune (Kean Svey District) is approximately 200 hectares. This much difference is possibly from the model computation and inadequate data. A clearly visualization is in Fig. 2, flood extent map showed the interesting part around a small island (situated in Kbal Kaoh Commune) at the upstream. The model does not contain the data about this island; that's why it compute as there is no object. Additionally, Samraong Thum Commune is the most damaged commune with an area about 800 hectares while Peam Mean Chey is the least affected about 15 hectare. From the map (Fig. 3) clearly showed that the simulated results seem to be greater than the observed. However, the model provides a good agreement with the observed flood when the measurement of fit value F1 and F2 are 0.86 and 0.74 respectively. Such a value is higher than values that accepted by another study [7]. This results can assume that HEC-RAS is able to simulate the damaged area from flooding effectively. 


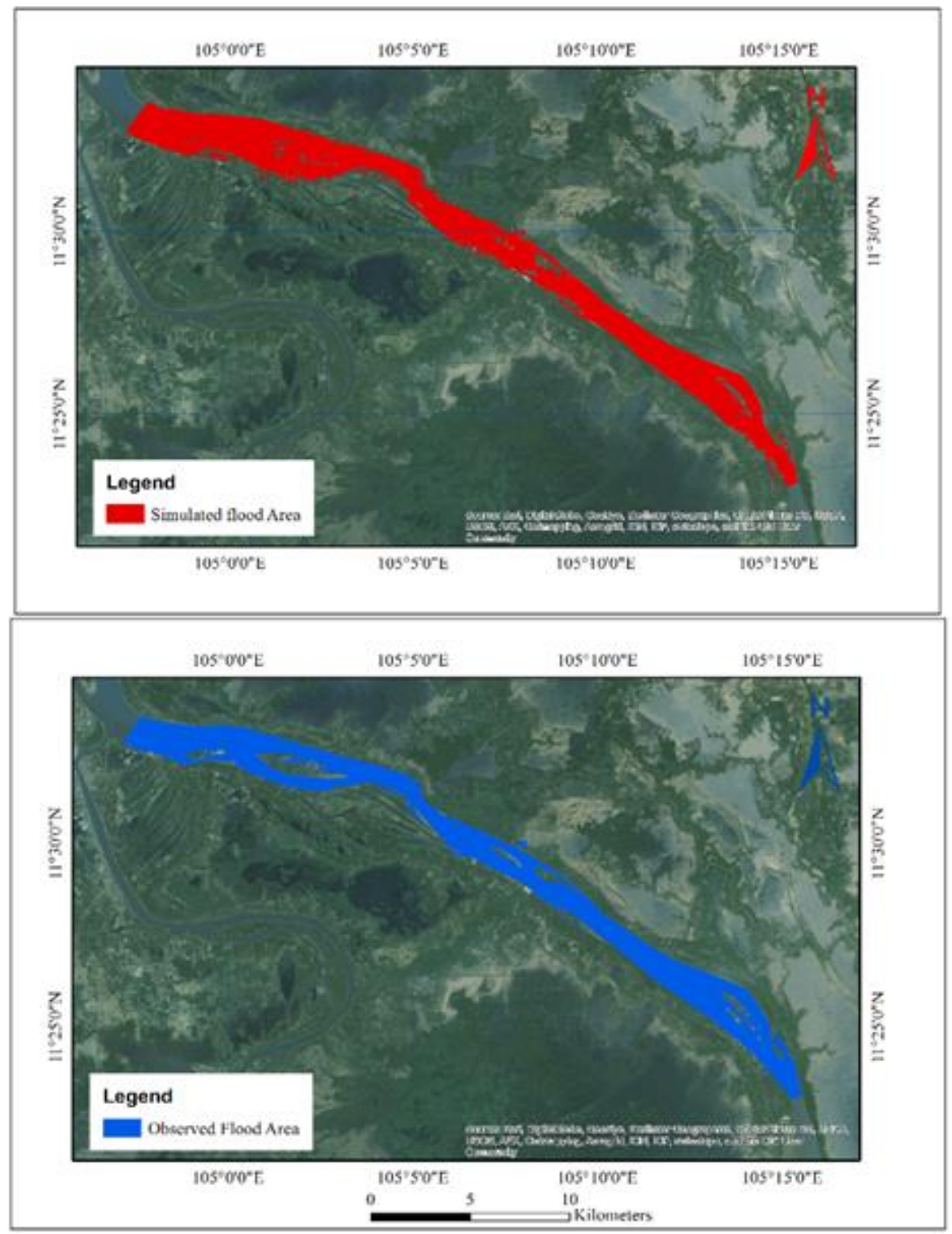

Fig. 3. Flood Map results from Simulation (Red) and Observed (Blue) at the same date (in Aguast 24, 2008).

\subsection{Performance on Flood Depth}

The column graph (Fig. 4) shows how much the difference between simulated and observed water level from 2000 to 2013. Based on the Error index such Nash-Sutcliffe Efficiency (NSE), and the Ratio of the root mean square error to the standard deviation of measured data (RSR), they indicated the value 0.99 and 0.088 respectively. According to the criteria, it provided the agreement that HEC-RAS simulated the water level in a very good performance rating. However, PBIAS valued +23.46 percent indicated the performance in satisfied rating.

From figures (Fig. 2 and Fig. 4), they showed that the affected area from simulation is greater and observation while simulated water level is less than observed water level in overall. However, it seemed to meet a confirmation from the research paper [8], it was confirmed that the flow came out of bank earlier than actual and the water surface elevation is a bit lower than in real situation. This error occurs because of HECRAS is a one-dimensional hydraulic model that is typically inconsequential for watershed-level analysis. 


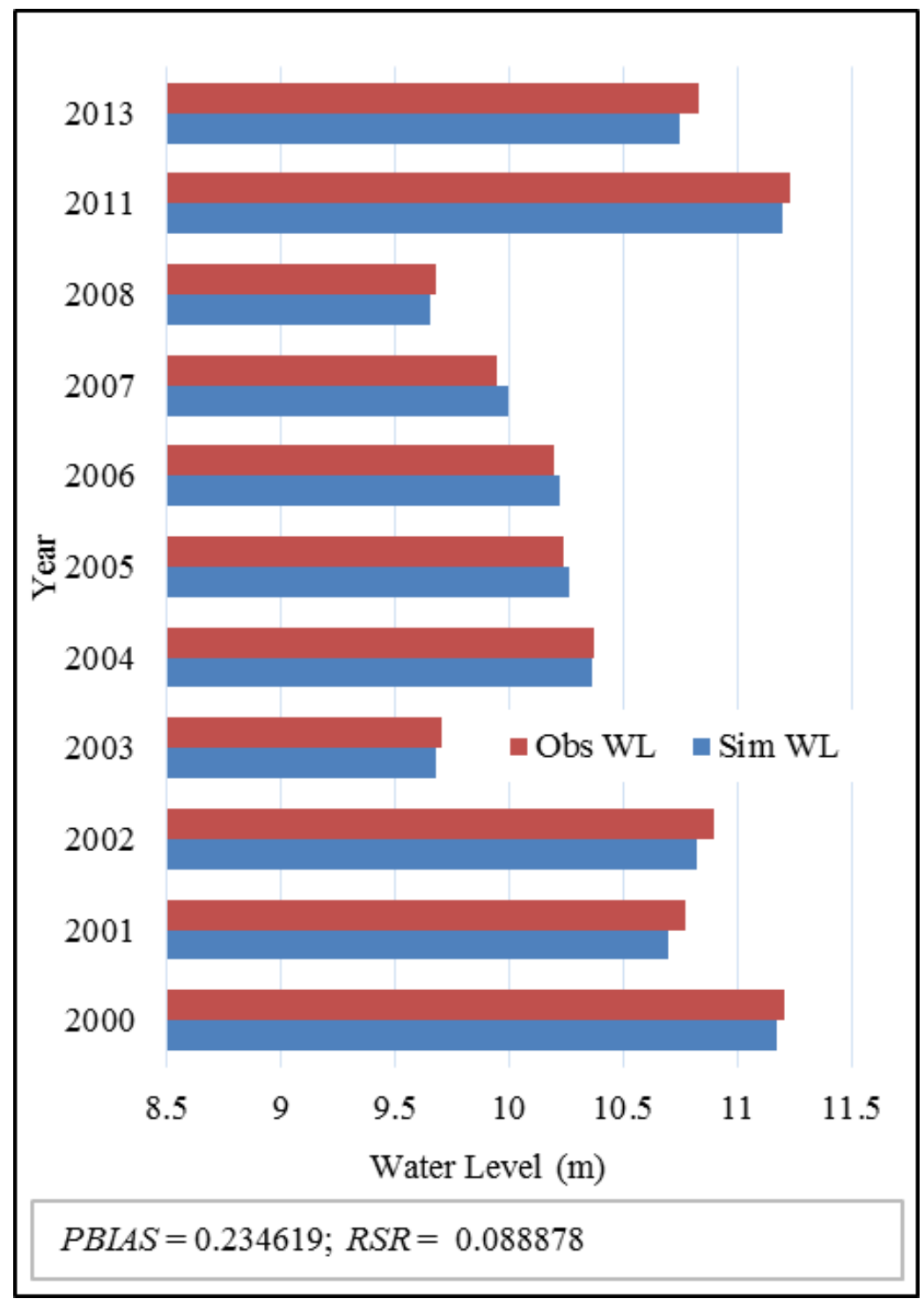

Fig.4. The difference between observed and simulation water level from 2000 to 2013 except 2009, 2010 and 2012.

\subsection{Flood Extent 2000-2013}

The total affect area in hectare was obtain from the simulation of peak discharge each year from 2000 to 2013. It was illustrated in Fig. 5 below. Additionally, the characteristics of flood varied from year to year and did not meet the overall trends.

The following maps are the results from water surface profile delineation. From graph and maps shown in, they express that the greatest flood affected including river around 12000 hectares while the least affected is about 6000 hectares respectively during 2011 and 2008 in 50 kilometers length of river. According to the flood situation report [5] and confirmed by National Committee for Disaster Management (NCDM) of Cambodia, it stated that the 2011 flood ranged the second biggest flood after flood in 2000. In contrast, the result from simulation expressed that the greatest flood occurred in 2011. This inconsistent result could be caused from water level assumption for Koh Norea Station because observed water level during 2011 is higher than 2000. The figure illustrated the flood extent map from 2000 to 2013 excluding 2009, 2010 and 2012 at the peak flow each year. Flood extent provided the information how much flood from the river affected both side along the river. Furthermore, the affected area both side of river including river is getting from the subtraction of total flood extent and river area (approximately $46 \mathrm{~km}^{2}$ ). Thus flood influenced to the both side of river made up of residential and rice field was from $14 \mathrm{~km}^{2}$ to $74 \mathrm{~km}^{2}$. 


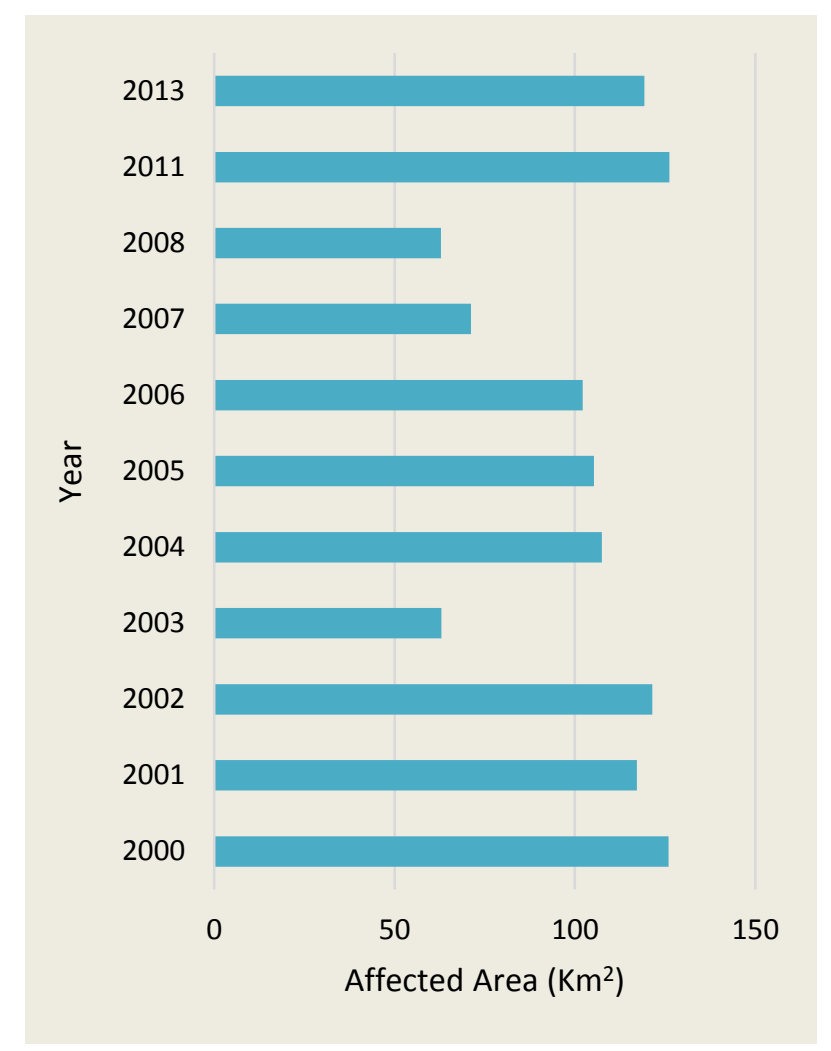

Fig. 5. The summary of total effected areas in $\mathrm{km}^{2}$ from 2000 to 2013 except 2009, 2010 and 2012.

\subsection{Flood Depth 2000-2013}

From the result shown in the figure (Fig. 4), it illustrates the difference between the peak observed and simulation water level from 2000 to 2013. In 2000 and 2011, it significantly showed the highest water level around 11.17 and $11.2 \mathrm{~m}$ respectively while 2008 was the year that did not have a great flood. Nevertheless, this maximum water level does not mean the flood depth above the residential area. From above maps, the model results gave a flood depth close to zero meters as a minimum to a maximum range from 9 to 11 meters according to maximum discharge. Flood depth maps (Fig. 6) also demonstrated the variation of depth along both side of the river. The degree of blue color indicated how level of water depth. For instance, the light blue showed the flood depth was almost zero; the heavy blue color was the maximum depth. All 11 flood depth map, the maximum of water level each year was at the upstream of study. Then water level started to decrease until downstream end of study area with its value around 5 or 6 meters. These result seem to verify with the water level at Chroy Chong Va Station (upstream) and Neak Leuong Station (downstream). 


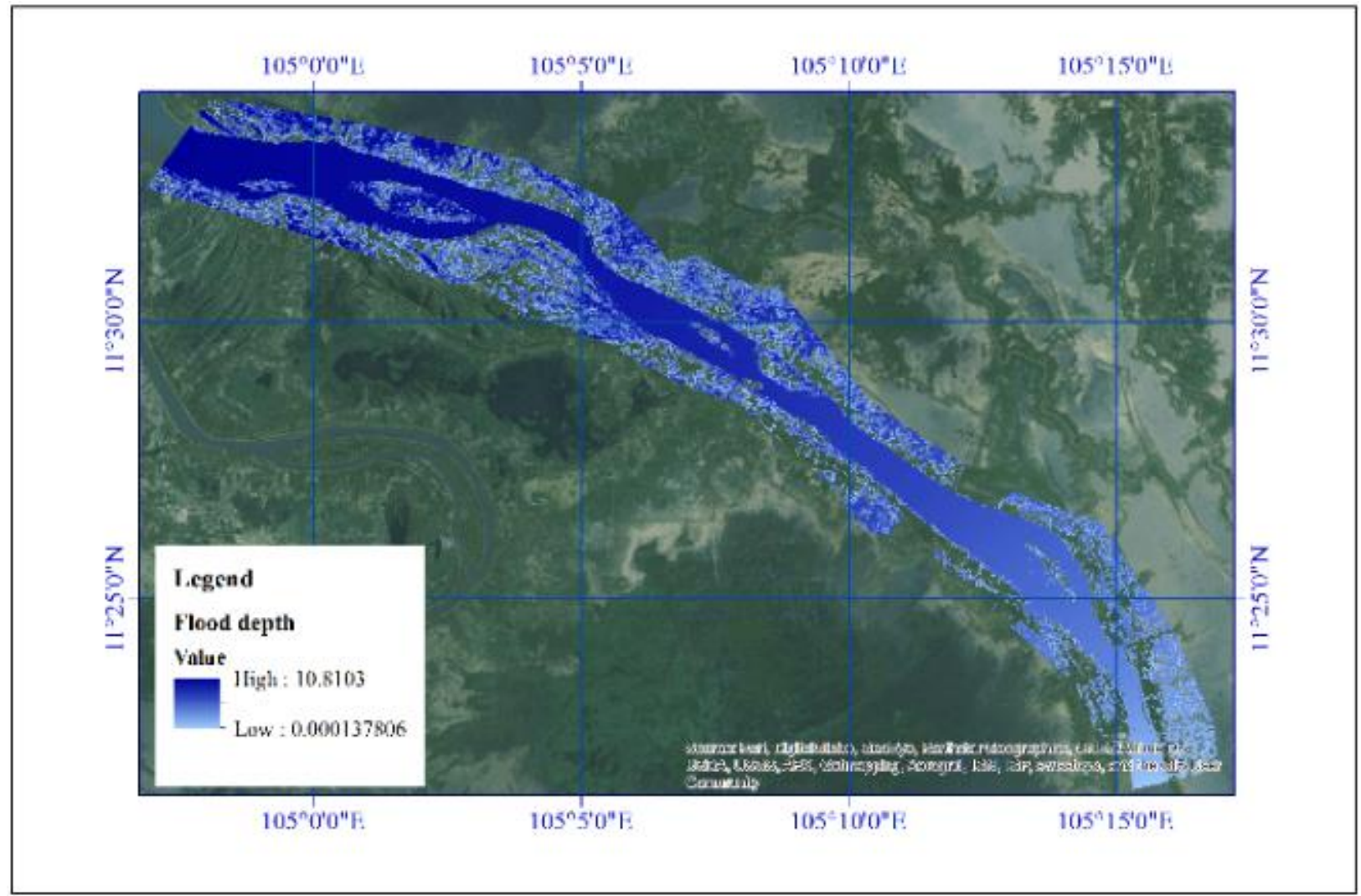

Fig. 6. Flood map from model simulation at the peak flow in 2000.

\section{Conclusions}

The study is attempted to apply the HEC-RAS model to compute the water surface profile through steady flow analysis. Thus the outcome (water surface profile) was generated into flood extent and flood depth in ArcGIS. Maps from 2000 until 2013 and 10-year return period flood were produce with the value of affected area and flood depth.

According to performance rating, the fit value F1 and F2 equal 0.86 and 0.84 respectively. Moreover, the value of RSE, RSR and PBIAS gave the value $0.99,0.088$ and 23.46 consequently; thus it prove that the efficiency of HEC-RAS model can be simulated and provided a satisfied results. In addition, HEC-RAS could give a valid output both affected area and flood depth. For the flood study from 2000 until 2013 and also 10year return period, the outputs both flood extent and flood depth including the river. The total affected area both side of this $50 \mathrm{~km}$ of river (excluding river area around $46 \mathrm{~km}^{2}$ ) was ranged from $14 \mathrm{~km}^{2}$ to $74 \mathrm{~km}^{2}$ (made of various land use such as residential, rice field and industrial area ) while flood depth was from zero to about 10 meters for both sides of river. However, there still were few assumption and errors for the study such as flood maps were produced based on discharge the upstream of the study while the actual event is that surface runoff from precipitation contributes for inflow into the river. Furthermore, river bank changing and other developments were not account with the study. Next, inadequate data for this study also contributes to the error also: DEM is low resolution thus it cannot detail every elevation changing; less cross-section make inaccurate river bathymetries such expansion and contraction.

Nevertheless, the integration between HEC-RAS and ArcGIS provides a facility for flood mapping for this study. The flood map from 2000 to 2013 and 10-years return period inundation map is the satisfied examples to this collaboration. Map produced by this model is really useful for development planning and also disaster management. All the results are able to conclude that HEC-RAS is a great hydraulic tool for primary flood Mekong River in a future study. Regardless the result, HEC-RAS is capable for flood studies. However, if HEC-RAS is used for the future study, it's recommended that the adequate data and field surveying are needed to run this model. DEM of study area should be a more high resolution in order to obtain more accurate result since elevation extraction and floodplain delineation are depended on DEM. In order to get more accurate flood result, another model such as HEC-HMS or SWAT should be used to 
simulate the surface runoff and be computed as an inlet discharge with upstream discharge. Moreover, field surveying including cross-section and floodplain is required to get more efficiency geometry data. Another importance, the water level should be measured at the first cross-section of the upstream. Last but not least, the latest version of HEC-RAS 5.1 is recommended to use because it is capable for flood study and flood map without ArcGIS anymore.

\section{Acknowledgement}

The study cannot be concluded without various local and international open sources. Water level and Discharge were provided from Ministry of Water Resources and Meteorology (MOWRAM). This research have been done under the Department of Rural Engineering of Institute of Technology of Cambodia (ITC). This work was supported by JSPS Core-to-Core Program. B. Asia-Africa Science Platforms.

\section{References}

[1] WorldAtlas. (2016). WorldAtlas [Online]. Available: http://www.worldatlas.com/as/kh/where-iscambodia.html

[2] S. Matsui, M. Keskinen, P. Sokhem, and M. Nakamura, "Tonle Sap: Experience and Lessons Learned Brief. World Lake Database, International Lake Environment Committee Foundation (ILEC), 1, 12, 2006. Available: http://www.ilec.or.jp /eg/ lbmi/ pdf/ 25_Lake_Tonle_Sap_27February2006.pdf

[3] (2015). The Climate of Cambodia [Online]. Available: http://www.geography-site.co.uk/pages/ countries/climate/cambodia_climate.html

[4] T. Welle, J. Birkmann, J. Rhyner, M. Witting, and J. Wolfertz. (2013). World Risk Report 2013 [Online]. Available: http://www.worldriskreport.org/fileadmin/PDF/2013/WorldRiskReport_2013_online.pdf

[5] Mekong River Commission, "MRC technical paper: Flood situation report 2011," Mekong River Commission, no. 36, pp. 1-59, 2011. Available: http://www.mrcmekong.org/assets/ Publications/technical/Tech-No36-Flood-Situation-Report2011.pdf [Accessed: 15 April 2014]

[6] G. W. Brunner, HEC-RAS River Analysis System: User's Manual. 2016.

[7] V. M. Quiroga, S. Kure, K. Udo, A. Mano, "Application of 2D numerical simulation for the analysis of the February 2014 Bolivian Amazonia flood: Application of the new HEC-RAS version 5," RIBAGUARevista Iberoamericana del Agua, vol. 3, no. 1, pp. 25-33, 2016. Available: http://doi.org/10.1016/j.riba.2015.12.001

[8] C. Goodell and C. Warren, "Flood inundation mapping using HEC-RAS," Obras y Proyectos, pp. 18-23, 2006. 